\section{GENETICS}

\section{Neurone Mapping}

WITH the current emphasis on experiments involving interference of one sort or another with the organism under study, Dr Sidney Brenner's talk to the Royal Society on April 22 was a startling reminder of what can still be achieved by means of pure description. Or almost pure, for his work involves the creation of nematode mutants by dosing with methyl ethane sulphonate, as well as genetic mapping of the ensuing mutations. Nonetheless, the most impressive part of Dr Brenner's recent work from the practical point of view is his painstaking neurone-by-neurone description of the nematode nervous system.

His aim essentially is to take the "molecular" out of molecular genetics and use its powerful methods for studying the specification of systems of cells in whole organisms. Nematodes were selected for several reasons. First, they are unquestionably animals, which, said Dr Brenner, could not strictly be said for amoebae and still less for slime moulds. Second, they have a $3 \frac{1}{2}$-day life cycle and each nematode produces 300 larvae at a time. Third, they can be stored in a state of suspended animation in liquid nitrogen until neededin other words, as Dr Brenner said, you can keep a file of mutants. And fourth, they have a singularly convenient reproductive arrangement. They are in general hermaphrodite, so that there is no difficulty in producing a completely isogenic population from one nematode if one is wanted; but about one nematode in 2,000 is male so that crosses are also possible. Male nematodes can be distinguished by their behaviour ("the same way that I know I'm male").

Because he wished to look at the nervous system, Dr Brenner was primarily interested in mutations which could be seen to interfere with movement. From his studies of mutants, he now has a genetic map of which an interesting aspect is that although there are extensive empty spaces on the chromosome diagram, the sites on which mutations were found seem to be saturated; Dr Brenner does not believe that this is an artefact of the mutagen he used. If this is true, it should be very interesting to evolutionary theorists.

Nematodes are about the diameter of an erythrocyte, so electrophysiology is out of the question. Dr Brenner has instead built up a three-dimensional map of the nematode nervous system using serial electron microscopical sections; he described some of his findings from three wild type specimens and three (". . . well, as the result of an accident, 2.9") mutants which he has designated UNC30. It turns out that the organization of the wild type nervous system is invariant; and more interesting still, that some of the neurones which displaced in the mutants are displaced in an invariant fashion. To find out precisely how these structural aberrations relate to the behaviour of the organism, Dr Brenner will need a total three-dimensional map of the nervous system of each phenotype. $\mathrm{He}$ is now engaged in trying to find out how to program a computer to store such a map at the same time as the genetic map, in the hope of elucidating the logic of the genetic control mechanism. This kind of approach-that of looking for the logic of a system rather than its detailed chemistry-is undoubtedly one that is gaining ground.

\section{GEOLOGY \\ African Events}

from a Correspondent

IN spite of the broad theme "Frontiers of Geological Research in Africa", the sixth colloquium on African geology held from April 14-17 at the University of Leicester dwelt for the most part on two topics: the detailed structure of the Precambrian basement and the mega-tectonics and magma control of the African plate. A notable feature of the colloquium was its informality: no speeches except a few impromptu ones, no delegates, no official business and no publications. The organizers merely made sure the purpose of the meeting was fulfilledthat geologists swopped ideas about Africa.

Mineralization, like granulites, received less attention than it should have done. Dr R. W. Henley (University of Manchester) suggested an ingenious thermal convective system whereby gold is precipitated in solid rock by a mass transfer of auriferous solutions across thermal gradients.

Much more was said when it came to discussing the structure of the African basement. Dr R. Caby (University of Montpellier) gave a clear exposition of the Precambrian history of the Hoggar Massif in the Sahara, and showed that the Suggarian and Pharusian both belong to one major orogenic cycle deformed 2,000 million years ago, and again later in the Pan African event $\sim 600$ million years ago, but Dr G. Vitel (University of Algiers) thought this was an oversimplification and redefined a more limited, early Suggarian facies of deformation. Dr P. W. G. Tanner (University of Leeds) gave an excellent account of Ruwenzori. Ancient gneisses $>2,500$ million years old are overlain by Toro metasediments deformed $\sim 2,000$ million years ago, and all have been affected by the Pan African event of 600 million years ago. Professor V. V. Beloussov (Moscow State University) said that although Ruwenzori is well known to

\title{
Isoucceptor tRNA as an Enzyme Inhibitor
}

AmONG the mysteries of protein synthesis is the problem of isoacceptor tRNAs. It is unclear why several tRNA species which accept the same aminoacid are universally encountered or why the pattern of these isoacceptor species sometimes changes when changes in cell metabolism occur such as during differentiation or viral infection. The work of Jacobson (reported in next Wednesday's Nature New Biology) provides an important clue to one possible physiological function of such a multiplicity of redundant tRNA species. He finds that one of the tyrosine tRNA isoacceptor species from Drosophila melanogaster can inhibit the enzyme tryptophan pyrrolase present in a vermilion mutant, although it does not affect the same enzyme from wild type Drosophila.

He takes as his starting point the earlier finding that tryptophan pyrrolase activity is practically absent in this vermilion mutant, although normally present in wild strains of Drosophila. But, by the simple expedient of treating crude homogenates of the mutant flies with $T_{1}$ ribonuclease, to destroy all the RNA therein, he was able to regenerate tryptophan pyrrolase activity within these extracts. On attempting to discover more exactly how this is brought about, he found that total unfractionated tRNA from wild type flies can inhibit once again the activated tryptophan pyrrolase. When this tRNA is fractionated chromatographically, it becomes clear that one of the tyrosine isoacceptor species is in fact responsible for the observed inhibition. He reports briefly the result of a remarkably elegant experiment confirming this finding. If the vermilion mutation is suppressed by the introduction of a further mutation, tryptophan pyrrolase activity is partially restored and the chromatographic peak attributable to the inhibitory tyrosine tRNA isoaccepting species disappears.

If these findings are more widely applicable, in that other iso-accepting tRNAs are also involved directly in regulating the activities of enzymes participating in intermediary metabolism and biosynthetic or degradative pathways, this would clearly be a major addition to the rule book of cell regulation as it is at present constituted. 